Gesnerus 66/2 (2009) 339-342

\title{
Book Notes
}

Johach, Eva: Krebszelle und Zellenstaat. Zur medizinischen und politischen Metaphorik in Rudolf Virchows Zellularpathologie. Freiburg i. Br., Rombach Verlag, 2008. 379 S. Ill. (Berliner Kulturwissenschaft, Bd. 5). € 49.20. ISBN 978-3-7930-9511-8.

L'ouvrage d'Eva Johach est issu d'une thèse de doctorat soutenue à l'Université Humboldt de Berlin. Il en porte les stigmates: organisation rigoureuse, découpage systématique des rubriques, bibliographie extrêmement fouillée - autant d'avantages pour un sujet passionnant, mais complexe, comme peut l'être la «métaphorologie», étude des métaphores appliquées à l'un de ses objets sans doute les plus féconds, le corps individuel (composé de myriades de cellules) et politique (l'Etat composé de myriades d'individus). On le sait depuis les travaux de Judith Schlanger au moins, le $\mathrm{XIX}^{\mathrm{e}}$ siècle est un terrain particulièrement propice pour une telle étude. Eva Johach se propose d'examiner plus spécifiquement la fonction des métaphores dans le discours scientifique de la pathologie cellulaire. Inspirée par la notion de style de pensée scientifique, dans lequel se nouent des représentations collectives et des concepts et méthodes stylistiques spécifiques selon Ludwik Fleck, elle démontre la signification des métaphores dans l'élaboration théorique de la problématique scientifique du cancer chez Rudolf Virchow, et, au-delà, les implications d'une étude qui tienne compte de cette dynamique et des dimensions sociales et politiques dans l'histoire du cancer, mais plus largement aussi de la biologie et de la médecine au XIX et au $\mathrm{XX}^{\mathrm{e}}$ siècle.

Vincent Barras, Lausanne

Medicine, Madness and Social History. Essays in Honour of Roy Porter. Ed. by Robert Bivins and John V. Pickstone. Basingstoke, Palgrave Macmillan, 2007. X, 295 p. Ill. $£$ 58.-. ISBN 978-0-230-52549-8.

Vingt collègues, collaborateurs et anciens étudiants de Roy Porter ont joint leurs efforts pour constituer ce volume d'essais à la mémoire et en l'honneur d'un historien d'une productivité, d'une générosité et d'une sociabilité hors du commun. Regroupés en trois grandes séries dont les titres au caractère convenu n'ajoutent guère à la lisibilité de l'ensemble («The Sciences of History and the Politics of Science», «Bodies, Commodities and Social Differences», «Minds, Identities and Social Order»), ils constituent un témoignage des rapports que Porter a entretenus avec l'historiographie anglo-saxonne de la médecine et de la santé, mais surtout attestent la sympathie éprouvée pour ce personnage peu banal par une communauté de chercheurs où l'on retrouve, entre autres, Dorothy Porter (sur Babbage et Birkbeck), Colin 